\title{
La explotación laboral de niños, niñas y adolescentes en el Ecuador
}

\section{Labour exploitation of children and adolescents in Ecuador}

\author{
Rously Eedyah Atencio-González \\ uq.rouslyatencio@uniandes.edu.ec \\ Universidad Regional Autónoma de los Andes, Quevedo \\ Ecuador \\ https://orcid.org/0000-0001-6845-1631 \\ Gabriel Alexander López-Sánchez \\ dq.gabrielals58@uniandes.edu.ec \\ Universidad Regional Autónoma de los Andes, Quevedo \\ Ecuador \\ https://orcid.org/0000-0003-3128-6948 \\ Priscila Elisa Veliz-León \\ dq.priscilaevl14@uniandes.edu.ec \\ Universidad Regional Autónoma de los Andes, Quevedo \\ Ecuador \\ https://orcid.org/0000-0002-2340-9349
}

Recepción: 15 de septiembre 2021

Revisado: 25 octubre 2021

Aprobación: 15 de noviembre 2021

Publicación: 01 de diciembre 2021 


\section{Estimado Editor (a):}

La explotación laboral, aparece como consecuencia de una vulneración de derechos a la que se encuentran expuestos niños, niñas y adolescentes en Ecuador, siendo el trabajo infantil un tema preocupante, donde día a día se ven niños realizando trabajos que todavía no les corresponden en su sano desarrollo como individuos. El trabajo exige responsabilidad, asimismo madurez para desempeñarlo, es por esa razón que los niños no están aptos, para poder ocuparse en estas funciones.

En este contexto, lamentablemente, son muchos los casos, en los que los niños, niñas y adolescentes, tienen la necesidad de hacerlo y en los peores casos son obligados por los padres a realizar dicha tarea. La (Organización Internacional del Trabajo, 1995 c.p Leiva, 2016) define al trabajo infantil como aquel que priva a los niños de su sano desarrollo, su potencial y su dignidad, y que es perjudicial desde un punto de vista tanto físico como psicológico, definición que tiene una gran relevancia, como el derecho que tienen los niños, niñas y adolescentes a realizar actividades propias de su edad y que permitan y fomenten el desarrollo de su intelecto, potencialidades y capacidades.

En este sentido, se han de tomar en cuenta los derechos de los niños, niñas y adolescentes, como por ejemplo el derecho a la educación, salud a la integridad física y psíquica en todos los entornos familiar, social y escolar. El Ecuador al estar suscrito a Convenios Internacionales, que tratan sobre la problemática que se aborda en esta investigación y al ratificar la Convención internacional para los Derechos del Niño, se comprometió a eliminar por completo el trabajo infantil, así como, a establecer en su normativa lo relacionado a la edad mínima para trabajar prevista en el (Convenio 138 de la OIT,1976) y por otra parte sobre las peores formas de trabajo infantil registradas en el (Convenio 182 de la OIT, 1999) contexto internacional adoptado por la legislación ecuatoriana. 
En este orden de ideas, estas medidas fijan las directrices para establecer un marco normativo que permita el acceso, al mismo tiempo que se active el derecho de protección para garantizar a los niños, niñas y adolescentes una vida digna y al mismo tiempo exterminar la explotación laboral económica y el desempeño de cualquier trabajo que pueda ser perjudicial o entorpezca el acceso a la educación, o que sea peligroso para su salud y desarrollo.

busca garantizar los derechos de los niños, niñas y adolescentes.

Por su parte, el Código de la Niñez y Adolescencia (2014):

Artículo. 81 establece que las niñas, niños y adolescentes tienen derecho a que el Estado, la sociedad y la familia les protejan contra la explotación laboral y económica y cualquier forma de esclavitud, servidumbre, trabajo forzoso o nocivo para su salud, su desarrollo físico, mental, espiritual, moral o social, o que pueda entorpecer el ejercicio de su derecho a la educación.

En este sentido, la norma eiusdem, conceptualiza al niño como sujeto de derechos, es decir un sujeto social; además, dispone que el Estado, la sociedad y la familia deben garantizar a niñas, niños y adolescentes su desarrollo integral y disfrute pleno de los mismos, en un marco de libertad, dignidad y equidad. Siendo este un derecho constitucional garantizado, tanto en la norma nacional como internacional, sin embargo, se ha observado que no existe una debida actuación por parte del Estado ecuatoriano a través de sus instituciones.

Así mismo, la Carta Magna establece la protección de los derechos de los niños contra el trabajo infantil, en el Ecuador la gran mayoría de niños, niñas y adolescentes, trabajan desde muy pequeños; dejando su época de niños, niñas y adolescentes como jugar, descansar, educarse, salud, buena alimentación; es por eso que el trabajo infantil vulnera sus derechos.

Por otro lado, en la Carta Suprema del Estado, determina lo siguiente:

Artículo 35. Niñas, niños y adolescentes, recibirán atención prioritaria y especializada en los ámbitos público y privado, así como esta misma atención prioritaria recibirán las personas en situación de riesgo, las víctimas de violencia doméstica y sexual, maltrato infantil, desastres naturales o antropogénicos. El Estado prestará especial protección a las personas en condición de doble vulnerabilidad. 
El Estado Ecuatoriano, por intermedio de sus instituciones ha venido realizando una labor constante para poder prevenir y erradicar el trabajo infantil, que en la actualidad existe una gran mayoría de niños, niñas a los cuales se les está vulnerando sus derechos establecidos en la (Constitución de la Republica del 2008), y en las legislaciones nacionales e internacionales; en donde se busca proteger los derechos de los niños, quienes pertenecen al grupo de atención prioritaria. Los derechos de los niños, niñas y adolescentes, garantizados tanto en la norma suprema nacional como internacional no se agotan, pero es necesario que las instituciones gubernamentales y no gubernamentales intervengan para que puedan participar y apoyar a la erradicación de la explotación laboral infantil; para poder efectivizar este derecho.

Los niños, niñas y adolescentes tienen derechos distintos a los de un adulto, pues ellos gozan de derechos especialísimos por su condición de doble vulnerabilidad, ya que los Estados por ser partícipes mediante la suscripción de sus convenios y las Organizaciones. Se considera que el trabajo infantil es una actividad que generalmente es peligrosa para los niños, niñas y adolescentes quienes practican a diario actividades que constantemente ponen en peligro su vida y su salud emocional y física; ya que las mismas no cuentan con protección para realizar las jornadas diarias, constituyéndose así en una continua pobreza en las familias que impiden el desarrollo del país.

En ecuador existe una legislación que es aplicable en contra del trabajo infantil a nivel nacional, pero sin embargo existe una escasez de programas locales en donde se trate acerca del trabajo infantil, para evitar así la vulneración de estos derechos; creándose así una necesidad de crear normas más rígidas y las mismas socialicen estos derechos a la niñez y adolescencia ecuatoriana. También, se cuenta con el Interés Superior, que busca consolidar las garantías, al respecto Paulette Murillo, et al, (2020) nos indican que:

Tal es la importancia, que actualmente el Estado ecuatoriano le concede a este principio que lo sitúa en la cima de la pirámide de las garantías para los derechos de las niñas, niños y adolescentes; de esta forma se convierte en un instrumento jurídico que protege y garantiza el cumplimiento de los derechos de la niñez y adolescencia y cuida porque todas las decisiones que de alguna manera tengan que ver con los intereses de este grupo no 
dañen su desarrollo integral y bienestar, y que siempre sean favorables a los mismos.(p.387)

\section{FINANCIAMIENTO}

No monetario.

\section{AGRADECIMIENTO}

A la Universidad Regional Autónoma de los Andes, Quevedo, por motivar el desarrollo de la Investigación.

\section{REFERENCIAS CONSULTADAS}

Asamblea Nacional Constituyente de la República del Ecuador, (2008). Constitución de la República del Ecuador. [Constitution of the Republic of Ecuador]. Montecristi. Registro Oficial 449 de 20-oct-2008. Recuperado de https://n9.cl/sia

Congreso Nacional. (2003). Código de la niñez y adolescencia. [ Childhood and Adolescence Code]. Quito. Recuperado de: https://n9.cl/fokqg

Leyva Piña, M., y Pichardo Palacios, S. (2016). ¿Un mundo sin trabajo infantil? [ ¿A world without child labour? El Cotidiano, (197),73-81. Recuperado de: https://n9.cl/zx6zy

Organización Internacional del Trabajo(2006).Trabajo infantil. Recuperado de: https://n9.cl/ock71

Paulette Murillo, K., Banchón Cabrera, J., y Vilela Pincay, W. (2020). El principio de interés superior del niño en el marco jurídico ecuatoriano. [ The principle of the best interests of the child in the Ecuadorian legal framework]. Revista Universidad y Sociedad, 12(2), 385-392. Recuperado de: https://n9.cl/9b9a 